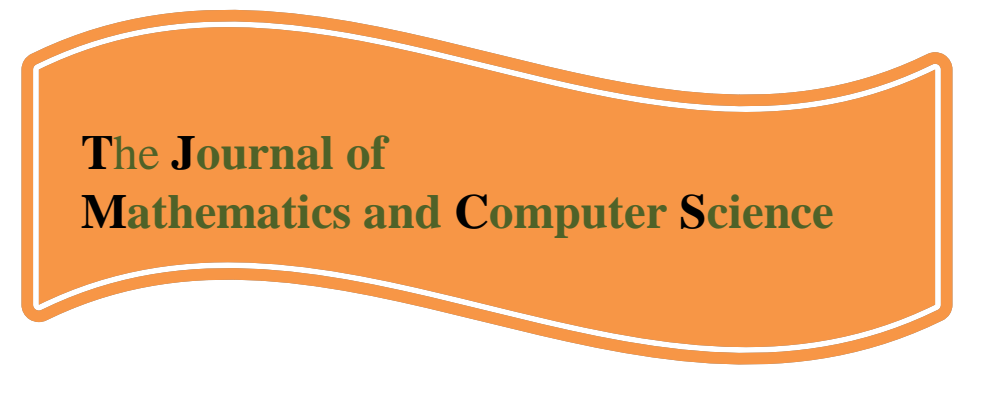

Available online at

\title{
http://www.TIMCS.com
}

The Journal of Mathematics and Computer Science Vol .4 No.4 (2012) 536-541

\section{Ranking decision making units by compromise programming}

\author{
Majid Darehmiraki \\ Department of Mathematics, Khatam Alanbia University of Technology, Behbahan, Khouzestan, Iran \\ email:darehmiraki@yhoo.com
}

\section{Zahra Behdani}

Department of Mathematics, Khatam Alanbia University of Technology, Behbahan, Khouzestan, Iran email: zbehdani@yahoo.com

\begin{abstract}
Data envelopment analysis (DEA) is a very useful management and decision tool. The ranking of decision making units (DMU) has become an important component in the decision process. In this paper we developed a new method for measuring the efficiency score of Decision-Making Units (DMUs) by using compromise programming. The proposed method calculates distance to the ideal for each DMU. The DMU with shorter distance to the ideal has better efficiency. A numerical example is provided to illustrate the application of the proposed DEA model.
\end{abstract}

Keywords: Data envelopment analysis, Ideal decision making (IDMU), Compromise programming

\section{Introduction}

In recent years, Data Envelopment Analysis (DEA) has become a central technique in productivity and efficiency analysis applied in different aspects of economics and management sciences.DEA is a nonparametric method of measuring the efficiency of a DMU such as a firm or a public sector agency, first introduced by Charnes, Cooper and Rhodes (CCR) in 1978 [2]. The efficiency score is measured as a ratio between a weighted sum of outputs and a weighted sum of inputs, even if the production function is unknown. The weights are chosen so as to find the best advantage for each unit to maximize its relative efficiency, under the restriction that this score is bound by unit efficiency. If a unit with its optimal weights receives the score efficiency of 1 , it is efficient, and for a score smaller than 1 it is inefficient. These optimal weights differ from unit to unit. There are DEA researchers that emphasize the difficulty to rank all the units on one scale, claiming that DEA provides only a dichotomy classification into two groups: efficient and inefficient. If the number of units is small relative to the number of inputs and outputs, most of the units will be efficient.

Within DEA is a sub-group of papers in which many researchers have sought to improve the differential capabilities of DEA and to fully rank both efficient, as well as inefficient, decisionmaking units. The ranking methods have been divided in this paper into six, somewhat overlapping, areas. The first area involves the evaluation of a cross-efficiency matrix, in which the units are self and peer evaluated. The second idea, generally knows as the super-efficiency method, ranks through the exclusion of the unit being scored from the dual linear program and an analysis of the 
change in the Pareto Frontier. The third grouping is based on benchmarking, in which a unit is highly ranked if it is chosen as a useful target for many other units. The fourth group utilizes multivariate statistical techniques, which are generally applied after the DEA dichotomic classification. The fifth research area ranks inefficient units through proportional measures of inefficiency. The last approach requires the collection of additional, preferential information from relevant decision-makers and combines multiple-criteria decision methodologies with the DEA approach. In this paper, we present a new approach for ranking DMUs in DEA. First, we calculate distance to IDMU for each DMU. Then, we order DMUs based on their distance to IDMU, smaller distance corresponding to upper ranking. The described idea in this paper is inspired of Kao [4].

The current paper is organized as follows. The next section, we give a ranking method by ideal DMU. A numerical example is provided in section 3. And the main idea of the paper is concluded in section 4 .

\section{Proposed method}

Assume that there are n DMUs to be evaluated, each DMU with m inputs and s outputs. We denote by xij $(i=1, \ldots, m)$ and yrj $(r=1, \ldots, s)$ the values of inputs and outputs of DMUj $(j=1, \ldots, n)$, which are all known and positive. An IDMU can be defined as follows:

Definition 1. [16] An IDMU is a virtual DMU, which can use the least inputs to generate the most outputs.

According to the above definition, we denote by $x_{i}^{\min }(i=1, \ldots, m)$ and $y_{r}^{\max }(r=1, \ldots, s)$ the inputs and outputs of the IDMU. They are determined by the following formulae:

$$
\mathrm{x}_{\mathrm{i}}^{\min }=\min _{\mathrm{j}}\left\{\mathrm{x}_{\mathrm{ij}}\right\}, \quad \mathrm{i}=1, \ldots, \mathrm{m} ; \quad \mathrm{y}_{\mathrm{r}}^{\max }=\max _{\mathrm{j}}\left\{\mathrm{y}_{\mathrm{rj}}\right\}, \quad \mathrm{r}=1, \ldots, \mathrm{s}
$$

The efficiency of any DMU is worse than that of the IDMU, no matter what weights are applied to individual input or output. Thus, we have $E_{j} / E^{*}<1$, where the efficiency of the DMUj is $E_{j}$ and the efficiency of the IDMU is $E^{*}$.

According to the implication of efficiency, the efficiency of the IDMU can be defined as

$$
E^{*}=\frac{\sum_{r=1}^{s} u_{r} y_{r}^{\max }}{\sum_{i=1}^{m} v_{i} x_{i}^{\min }}
$$

In order to standardize the weights $\mathrm{u}_{\mathrm{r}}$ andv $\mathrm{v}_{\mathrm{i}}$, the efficiency of IDMU must be equal to 1 . The difference between $E_{j}$ and 1 , bys $s_{j}$, is the relative distance between the DMUj and the IDMU. Thus efficiency of DMUj is $1-s_{j}$. The problem is then transformed to finding the set of weights $u_{r} a_{n} v_{i}$, which produce the smallest total squared difference between the efficiency of DMU and that of the IDMU. The associated model is:

$$
\begin{gathered}
\min \sum_{j=1}^{n} s_{j}^{2} \\
\text { s.t. } \frac{\sum_{r=1}^{s} u_{r} y_{r j} j}{\sum_{i=1}^{m} v_{i} x_{i j}}+s_{j}=1 \quad j=1, \ldots, n \\
\frac{\sum_{r=1}^{s} u_{r} y_{r}^{\max }}{\sum_{i=1}^{m} v_{i} x_{i}^{\min }}=1 \\
v_{i} \geq \varepsilon, u_{r} \geq \varepsilon, s_{j} \geq 0, i=1, \ldots, m ; r=1, \ldots, s
\end{gathered}
$$

Using Charnes and Cooper transformation, the above fractional programming model can be solved through the following nonlinear programming model:

$$
\min \sum_{j=1}^{n} s_{j}^{2}
$$


M. Darehmiraki, Z. Behdani / TJ MCS Vol .4 No.4 (2012) 536-541

$$
\begin{gathered}
\text { s.t. } \sum_{r=1}^{s} u_{r} y_{r j}+\left(s_{j}-1\right) \sum_{\substack{i=1 \\
s}}^{m} v_{i} x_{i j}=0, \quad j=1, \ldots, n \\
\sum_{\substack{r=1 \\
m}}^{m} u_{r} y_{r}^{m a x}=1 \\
\sum_{i=1}^{m} v_{i} x_{i}^{m i n}=1 \\
v_{i} \geq \varepsilon, u_{r} \geq \varepsilon, s_{j} \geq 0, i=1, \ldots, m ; r=1, \ldots, s
\end{gathered}
$$

Note that the distance variable $s_{j}$ is always positive because every DMUj is dominated by the IDMU.

The efficiency of DMUj is $1-s_{j}$.

In model (2), we consider a virtual DMU as IDMU and assigned the one score to it as a benchmark to this virtual DMU such that for other DMUs is got

$$
\frac{\sum_{\mathrm{r}=1}^{\mathrm{s}} \mathrm{u}_{\mathrm{r}} \mathrm{y}_{\mathrm{rj}}}{\sum_{\mathrm{i}=1}^{\mathrm{m}} \mathrm{v}_{\mathrm{i}} \mathrm{x}_{\mathrm{ij}}} \leq 1 \quad \mathrm{j}=1, \ldots, \mathrm{n}
$$

As a geometrical interpretation, IDMU $\left(\sum_{\mathrm{i}=1}^{\mathrm{m}} \mathrm{v}_{\mathrm{i}} \mathrm{x}_{\mathrm{i}}^{\min }, \sum_{\mathrm{r}=1}^{\mathrm{s}} \mathrm{u}_{\mathrm{r}} \mathrm{y}_{\mathrm{r}}^{\max }\right)$ is point in $\mathrm{R}^{2}$ and the benchmark is a straight line that passes through the origin with gradient one. Then $v_{i}, u_{r}(i=1, \ldots, m, r=$ $1, \ldots, \mathrm{s})$ must be determined such that the distance between these points and the benchmark line be as small as possible. In order to don't solve a fractional programming, (2) is transformed to (3). Therefore (2) and (3) are equivalent.

In model (3) if set $Y_{j}=\sum_{r=1}^{s} u_{r} y_{r j}$ and $X_{j}=\sum_{i=1}^{m} v_{i} x_{i j}$ is got

$$
\begin{gathered}
\sum_{r=1}^{s} u_{r} y_{r j}+\left(s_{j}-1\right) \sum_{i=1}^{m} v_{i} x_{i j}=0 \Rightarrow Y_{j}-\lambda_{j} X_{j}=0 \quad\left(0 \leq \lambda_{j} \leq 1\right) j=1, \ldots, n \\
\Rightarrow \lambda_{j}=\frac{Y_{j}}{X_{j}} \quad j=1, \ldots, n
\end{gathered}
$$

Note that the efficiency of jth DMU is $\lambda_{j}$. Since $\lambda_{j}$ is the complement of $s_{j}$, as it is clear from the first set of constraints in models (2) and (3), the DMU with the smallest distance to the ideal, $s_{j}$, obviously has the largest efficiency, $\lambda_{j}$. In model (3), constraints two and three are applied in order to standardize weights.

Geometrically, in model (3), $v_{i}, u_{r}(i=1, \ldots, m, r=1, \ldots, s)$ must be determined such that slop of lines $Y_{j}-\lambda_{j} X_{j}=0(j=1, \ldots, n)$ be nearest value to 1 .

\section{Numerical example}

In this section, we use set of DMUs shown in Table 1 [6] to make an experiment to compare the calculation results of the proposed ranking model with AP method [1], MAJ model [5], Revised MAJ model [12], SA-DEA model [13], L1 norm model [7], Tchebycheff norm model [8], CSW model [3], Gradient line model [9], Advantage model [10], SBM model [14,15] and Mont carlo model [11]. The results are shown in Table 2 . The non-Archimedean infinitesimal was set as $\varepsilon=10^{-9}$. 
M. Darehmiraki, Z. Behdani / TJ MCS Vol .4 No.4 (2012) 536-541

Table 1. Data [6]

\begin{tabular}{|c|c|c|c|c|c|c|c|}
\hline Units & I1 & I2 & I3 & I4 & I5 & 01 & 02 \\
\hline DMU1 & 583 & 8 & 2.75 & 16.731 & 17129300 & 285 & 0.8848 \\
\hline DMU2 & 741 & 8 & 2 & 18.999 & 8903705 & 95 & 0.8597 \\
\hline DMU3 & 600 & 7 & 2.75 & 19.437 & 15864760 & 307 & 0.9226 \\
\hline DMU4 & 593 & 8 & 2.75 & 19.326 & 14802089 & 260 & 0.8928 \\
\hline DMU5 & 746 & 7 & 2 & 20.125 & 8398300 & 154 & 0.812 \\
\hline DMU6 & 992 & 9 & 2.75 & 21.821 & 19330020 & 254 & 0.8624 \\
\hline DMU7 & 775 & 8 & 2.75 & 13.333 & 17182320 & 292 & 0.9109 \\
\hline DMU8 & 1852 & 14 & 3.25 & 21.696 & 30126900 & 473 & 0.8632 \\
\hline DMU9 & 625 & 5 & 2 & 16.285 & 7638220 & 106 & 0.8898 \\
\hline DMU10 & 673 & 6 & 2 & 16.789 & 8659940 & 148 & 0.8668 \\
\hline DMU11 & 423 & 6 & 2 & 13.304 & 10799980 & 151 & 0.9435 \\
\hline DMU12 & 1292 & 18 & 3.25 & 18.333 & 47102720 & 782 & 0.9571 \\
\hline DMU13 & 1300 & 8 & 2.75 & 17.730 & 17451040 & 288 & 0.8996 \\
\hline DMU14 & 582 & 8 & 2.75 & 19.178 & 15850628 & 260 & 0.9054 \\
\hline DMU15 & 620 & 8 & 2 & 16.056 & 7938560 & 124 & 0.8744 \\
\hline DMU16 & 1256 & 10 & 2.75 & 21.516 & 23034560 & 378 & 0.8465 \\
\hline DMU17 & 765 & 10 & 2.75 & 19.145 & 15692740 & 303 & 0.8945 \\
\hline DMU18 & 842 & 7 & 2.75 & 16.972 & 8029240 & 153 & 0.9074 \\
\hline DMU19 & 1011 & 4 & 2.75 & 17.692 & 7702609 & 57 & 0.8764 \\
\hline DMU20 & 1128 & 9 & 2.75 & 21.927 & 22143650 & 357 & 0.9028 \\
\hline DMU21 & 3456 & 18 & 3.5 & 20.217 & 24892550 & 393 & 0.9195 \\
\hline
\end{tabular}


M. Darehmiraki, Z. Behdani / TJ MCS Vol .4 No.4 (2012) 536-541

\begin{tabular}{llllllll} 
DMU22 & 1008 & 3 & 2.25 & 10.213 & 7405200 & 36 & 0.8611 \\
DMU23 & 910 & 4 & 2.25 & 12.941 & 8839280 & 72 & 0.7735 \\
& & & & & & & \\
\hline
\end{tabular}

Table 2. Ranking of efficient units and compare proposed method with other methods.

\begin{tabular}{|c|c|c|c|c|c|c|c|c|c|c|}
\hline Model & D3 & D4 & D7 & D9 & D10 & D11 & D12 & D15 & D18 & D22 \\
\hline $\mathbf{A P}$ & 4 & 8 & 7 & 5 & 9 & 2 & 1 & 10 & 6 & 3 \\
\hline MAJ & 4 & 6 & 5 & 7 & 9 & 3 & 1 & 10 & 8 & 2 \\
\hline Revised MAJ & 4 & 8 & 6 & 5 & 9 & 3 & 1 & 10 & 7 & 2 \\
\hline SA-DEA & 4 & 8 & 7 & 5 & 9 & 2 & 1 & 10 & 6 & 3 \\
\hline L1 norm & 2 & 4 & 3 & 8 & 7 & 10 & 1 & 6 & 5 & 9 \\
\hline $\begin{array}{c}\text { Tchebycheff } \\
\text { norm }\end{array}$ & 4 & 7 & 5 & 9 & 8 & 2 & 1 & 10 & 6 & 3 \\
\hline CSW & 3 & 5 & 8 & 11 & 6 & 2 & 1 & 9 & 4 & 22 \\
\hline Gradient line & 4 & 8 & 7 & 5 & 9 & 3 & 1 & 10 & 6 & 2 \\
\hline Advantage & 13 & 15 & 4 & 5 & 8 & 3 & 2 & 7 & 6 & 1 \\
\hline SBM & 4 & 8 & 6 & 5 & 9 & 3 & 1 & 10 & 7 & 2 \\
\hline Mont carlo & 5 & 3 & 1 & 6 & 10 & 2 & 4 & 9 & 8 & 7 \\
\hline $\begin{array}{c}\text { Proposed } \\
\text { method }\end{array}$ & 8 & 9 & 7 & 3 & 5 & 1 & 2 & 4 & 10 & 6 \\
\hline
\end{tabular}

Note: the data with gray background color, the unit is infeasible in that model.

\section{Conclusions}

This paper present a new model for ranking DMUs based on compromise programming. In this model ideal DMU is defined. Then, DMUs are ranked based on distance to ideal DMU, smaller distance corresponding upper rank. The example given in this paper illustrates the advantages, potential and application of the proposed DEA models. Comparing with the exiting approaches, it is reasonable and efficient. Additionally, the proposed approach can provide decision makers with a new alternative to rank DMUs. 


\section{References}

[1] P. Anderson, , N.C. Petersen, A pdrocedure for ranking efficient units in data envelopment analysis. Management science 39 (10) (1993), 1261-1264

[2] A. Charnes, W.W. Cooper, E. Rhodes, Measuring the efficiency of decision making units. European Journal of Operation Research 2 (1978), 429-444

[3] F. Hosseinzadeh Lotfi, G.R. Jahanshahloo, A. Memariani, A method for finding common set of weights by multiple objective Programming in data envelopment analysis. Southwest journal of pure and applied mathematics 1 (2000), 44-54

[4]C. Kao, Weight determination for consistently ranking alternatives in multiple criteria decision analysis. Applied Mathematical Modelling, 34 (2009), 1779-1787

[5] S. Mehrabian, M.R. Alirezaee, G.R. Jahanshahloo, A complete efficiency ranking of decision making units in data envelopment analysis. Computational optimization and applications 4 (1999), 261-266

and applied mathematics 1 (2000), 44-54

[6] G.R. Jahanshahloo, F. Hosseinzadeh Lotfi, M. Sanei, Review of ranking models in dataenvelopment analysis, Applied mathematical sciences 2(29) (2008), 1431-1448

[7]G.R. Jahanshahloo, F. Hosseinzadeh Lotfi, N. Shoja, G. Tohidi, S. Razavian, Ranking using norm in data envelopment analysis. Applied mathematics and computational 153 (1) (2004), 215-224

[8] G.R. Jahanshahloo, F. Hosseinzadeh Lotfi, F. Rezai Balf, H. Zhiani Rezai, D. Akbarian, Ranking efficient DMUs using tchebycheff norm. Working Paper (2004)

[9] G.R. Jahanshahloo, M. Sanei, F. Hosseinzadeh Lotfi, N. Shoja, Using the gradient line for ranking DMUs in DEA. Applied mathematics and computation 151(1) (2004), 209-219

[10] G.R. Jahanshahloo, M. Sanei, N. Shoja, Modified ranking models, using the concept of advantage in data envelopment analysis. Working paper (2004)

[11] G.R. Jahanshahloo, F. Hosseinzadeh Lotfi, F. Rezai Balf, H. Zhiani Rezai, Using mont carlo method for ranking efficient units. Aplied Mathematic and Computation, 162 (2005), 371-372

[12] M.S. Saati, M. Zarafat Angiz, G.R. Jahanshahloo, A model for ranking decision making units in data envelopment analysis. Recrca operative vol.31 (1999)

[13] T. Sueyoshy, DEA nonparametric ranking test and index measurement: Slack-adjusted DEA and an application to Japanese agriculture cooperatives. Omega, INT.J.MGMT.SCI 27 (1999), 315-326

[14] K. Tone, A slack-Based measure of efficiency in data envelopment Analysis. European journal of operational research 130 (2001), 498-509

[15] K. Tone, A slack-bsed measure of efficiency in data envelopment Analysis. European journal of operational research 143 (2002), 32-41

[16] Y-M. Wang, Y. Luo, DEA efficiency assessment using ideal anti-ideal decision making units, Applied mathematics and computation, 173 (2006), 902-915 